\title{
Language Variation: A Case Study of Gender Differences in Wolof-French Codeswitching
}

\author{
Hafissatou Kane \\ Department of English Studies, Cheikh Anta DIOP University, Dakar, Senegal \\ Email address: \\ kanehafi@gmail.com \\ To cite this article: \\ Hafissatou Kane. Language Variation: A Case Study of Gender Differences in Wolof-French Codeswitching. International Journal of \\ Language and Linguistics. Vol. 8, No. 4, 2020, pp. 122-127. doi: 10.11648/j.ijl1.20200804.11
}

Received: April 30, 2020; Accepted: June 11, 2020; Published: June 20, 2020

\begin{abstract}
Research on how gender affects language have been long documented by several studies in the world. In many of these works, mostly done in variationist sociolinguistics, it has been claimed that women and men are different in their speech from one another. The paper investigates gender variation in Wolof-French codeswitching. More specifically it examines how male and female codeswitching are different in terms of frequency, types and other linguistic forms. The conversations of twelve Wolof-French bilingual students and office workers are analysed in this study. Results from this study show that women codeswitch more frequently than men. The study also indicates that intra-sentential codeswitching is the mostly used type in men's and women's speech. It has also been shown that the French discourse marker "quoi" is far more used in men speech and constitutes then a linguistic feature that differentiates men and women language. However, even if both genders prefer intra-sentential types of codeswitching, women tend to use it more $61,44 \%$ of their speech against $56,66 \%$ for men. Men, on the other hand, produce more inter-sentential codeswitching instances than women $13,02 \%$ against $12,53 \%$.
\end{abstract}

Keywords: Gender, Language Variation, Wolof, French, Codeswitching

\section{Introduction}

Codeswitching $^{1}$ (hereafter CS) is generally defined as the use of more than one code or language in a conversation or speech act that can involve a word, a phrase, a sentence, or several sentences. This switch can be inter-sentential (between sentences) and intra-sentential (within sentence boundaries).

To clarify the use of the term 'codeswitching' and other related phenomena, $[3,2]$ explain that code changing referred to using one code in one sentence and another code in the second sentence of the same speech event. This is different from code mixing which was defined as a use of free and bound morphemes from different codes in the same sentence while codeswitching was used as a cover term for both code changing and code mixing. However, some scholars still use the term code mixing but as a cover term for all types of CS

1 It has to be noted that some scholars spell the word with a space and write it in two words, i.e., code switching or with a hyphen, i.e., code-switching while Myers-Scotton and her associates use it as one word namely, codeswitching. In this study, I adopt Myers-Scotton's one-word spelling. (intra-sentential and inter-sentential), while most studies use the term codeswitching to refer to the phenomenon in language contact. For the purpose of this study I refer to the use of free or bound morphemes from more than one source language in the same conversation as codeswitching.

People codeswitch for many reasons. Dzameshie argues that the principle of code choice is "tacit knowledge that is possessed by all bilinguals and it forms part of their communicative competence" [6]. This knowledge is what guides them in their day-to-day interactions. He further explained that for a bilingual or monolingual, the basic and universal motivation behind the use of one's competence is the desire to maximize the full benefits of one's competence in social encounters. Hence, in communicating, a bilingual will employ codeswitching which is the code that provides the greatest reward to his communication need.

Codeswitching has received a lot of attention over the years. [4] notes that even though earlier works focused on bilingual communities in the United States of America, works were done later in other regions of the world. These works were initially done on Indo-European languages, but gradually, interest grew in languages that are not Indo- 
European. This interest led to the expansion of research into codeswitching.

In Senegal, several works have been conducted in this field. Nevertheless, the existing literature shows that these studies mainly investigate two aspects: sociolinguistic and linguistic features. For instance, [23, 17, 8] used the sociolinguistic approach which considers motivations for codeswitching such as setting, topic, domain, participants, and language functions. Other researchers have adopted the purely linguistic or grammatical approach largely concentrated on finding universally applicable, predictive grammatical constraints on codeswitching. These include $[19,14,11,12]$, to name but a few.

The present study examines gender difference in codeswitching between Wolof and French languages in Senegal. This will contribute to the existing studies on codeswitching and shed light on how language usage can vary according to gender, an area which has received no attention in the studies on code-switching within a Senegalese context. In this respect the objectives of this study are the following:

1. To investigate the frequency of codeswitching occurrences in the speech of both female and male Wolof-French speakers;

2. To identify the main types of codeswitching mostly used by these speakers

3. To discuss linguistic features that can further differentiate male and female CS.

\section{Literature Review}

This review of literature involves two sections. It first reviews basic issues discussed in the literature of gender and language that help to better understand this study. The second section focuses on works done on gender and codeswitching.

\subsection{Gender and Language}

'Gender and language' is generally defined as an area of study which is concerned with the investigation of varieties of speech associated with a particular gender, or social norms for such gendered language use. According to Corbet in [21] 'gender and language' is not an approach. Rather, it, can be best described as a topic, or more broadly, 'field' of study. Within linguistics, gender and language study has links not only with sociolinguistics, discourse analysis and language change, but also within stylistics, pragmatics, literacy, the history of language and even historical and descriptive linguistics.

In her book 'Language and Gender', [21] reports some works on language change including $[13,25,13]$ claims that there are two general principles regarding sexual differentiation in sociolinguistics. The first principle states that in a stable sociolinguistics stratification, men use a higher frequency of non-standard forms than women. This implies that women are more receptive to standard forms and that have apparent social prestigious forms. The second principle states that in majority of linguistic changes noted women use higher frequency of incoming forms than men.

In his study in the USA looking at the use of the short vowel /a/, [13] found that women in New York tended to style-shift far more than did male informants, and that they tended to be less conservative linguistically. They were in fact initiating change by using an 'advanced' vowel form in casual speech (the merging of /i h / and /e h /. In contrast, and a reminder of the variability of any gender-language relationship, [13]'s study of the two diphthongs /aw/ and /ay/ in Martha's Vineyard showed men to be leading change. In another reminder of variability, in [13], 'The intersection of sex and social class in the course of linguistic change', Labov notes that whereas men tend to use more non-standard stable forms than women, when it comes to linguistic change, women will innovate, in part by favouring new prestige forms "from above".

In his paper "Sex, covert prestige and linguistic change in the urban British English of Norwich", Trudgill correlates phonetic and phonological variables with social class, age, and stylistic context. However, following Labov, he was also interested in biological sex as a sociolinguistic variable. He used a quantitative methodology that was based on a language-scale interview study (a random sample of sixty people). Looking at the variable (ng), for which there are two pronunciations in Norwich English ('walking', the prestige form, and 'walkin'), Trudgill found that women tended to use the prestige forms of the other phonetic variables. He also found that women (more than men) tended to cover-report their pronunciation.

From these above-mentioned studies, it can be noted that when there is a new form introduced in a language system, women are more likely than men to adopt these new forms.

\subsection{Codeswitching and Gender}

[9] affirms that the long-established findings stating that women use more standard forms than men, derived from monolingual settings, were also usefully tested in bilingual contexts. Studies were carried out to investigate whether women use more standard forms of language than men in codeswitching. It is in this sense that she conducted a research, using transcribed recordings from two immigrant communities in the UK, the Greek Cypriots and the Punjabis, to test this hypothesis. After analysis, it was revealed that the results were negative. There were no significant differences between men and women in either community regarding the use of any kind of codeswitching, though, it was to recognize that there were substantial differences between the two communities both as regards quantity and type of codeswitching.

Some other studies, on the other hand, have found differences in either the amount or the type of codeswitching used by women and men within the same community. For instance, [19] shows that women engage in intra-sentential codeswitching more often than men in New York Puerto Rican community. [10] Reports a study they conducted in Nairobi, Kenya. In that study, it was uncovered that, women codeswitch more than men do. Out of 373 instances of CS, 
193 were done by females and 180 by males. Though, it was reported that any time both genders engage in a single conversation, males were found to engage in codeswitching more. They further explain that, male speakers tend to use more non-standard forms while communicating with females. They finally indicate that out of 333 instances of unswitched codes, males and females used 172 and 161 respectively, meaning that men tend to use more archaic forms than females who tend to use new forms.

As previously mentioned, the present study examines how male and female languages are different through WolofFrench codeswitching. For that the following questions should be addressed:

1. Between Wolof and French languages which gender codeswitch more?

2. Which gender uses more intra-sentential codeswitching and which one uses more inter-sentential type of codeswitching?

3. What other linguistic features are present in men's codeswitching but are rare or absent in women speech; and vice versa?

\section{Hypotheses}

Most studies in the literature agree that men use a higher frequency of non-standard forms in language. On the other hand, it has also been assumed that, linguistically, codeswitching is a non-standard variety of language. Then, it can be expected that men codeswitch more frequently than women in Wolof.

From the above-mentioned literature, I also predict that women will use more intra-sentential forms in Wolof-French codeswitching; and men, on the other hand, will use the greater number of inter-sentential forms of codeswitching.

This study finally predicts that if there is any linguistic feature that can differentiate men's and women's codeswitching, this feature will come from women, the gender which is more willing to adopt incoming forms in language.

\section{Methodology}

The sample used in this study is an extract from the data of my doctoral thesis. Two mixed conversations of twelve participants have been analysed. In the first conversation, there is four men and one woman. The woman was 28 while the male participants were between 30 and 37 years old. They were all working at the Senegalese Virtual University and have at least a Master's degree. They discussed some social questions suggested by the researcher. These issues were related to divorce in young couples, children in divorced couples, combining professional and family life for a woman and celibacy of graduated women. These participants were all aware that their conversation was being recorded but they didn't know that it would be used for a codeswitching study. They believed that the researcher only needed their opinions about these social issues. This approach was chosen in order to keep the interactions natural.

The second conversation was recorded from a TV program dealing with youth issues. That day, the entertainer was at the campus of Cheikh Anta Diop University and discussed with a group of students involving two male and four female students. The discussion was about sexuality in the campus. The participants' age was not indicated, except one female student who mentioned that she was 22 years old.

In both conversations, the 12 participants talked in a very informal situation and resorted to Wolof-French codeswitching in a very natural way.

\section{Findings and Discussion}

After analysing the above-mentioned codeswitched conversations, it has been found that men and women exhibit language variation in their speech. These differences can be seen through codeswitching frequency, the types of codeswitching (intra-sentential and inter-sentential) and finally through the French discourse markers ("quoi").

\subsection{Gender Variation in Codeswitching Frequency}

The first research question explores the difference between male and female Wolof-French codeswitching in terms of frequency. This difference is examined, first, by determining each participant's codeswitched utterances (both intrasentential and inter-sentential types). This comparison allows us to identify the speakers who codeswitch more, on the one hand. But, it also helps to identify who between male and female bilinguals perform the greater cases of CS. Table 1 and 2 below respectively show the two conversations providing the present data. Each table presents the switched and unswitched forms of each participant. They also present the participants' total intra-sentential and inter-sentential codeswitches; and the frequency they switch between the two languages.

Table 1. Frequency of men's and women's codeswitching (Conversation 1).

\begin{tabular}{llll}
\hline Participants & Total utterances & Total switches & Frequency \\
\hline Male 1 & 207 & 148 & $71,5 \%$ \\
Male 2 & 69 & 49 & $71 \%$ \\
Male 3 & 39 & 30 & $76,9 \%$ \\
Male 4 & 108 & 87 & $80,5 \%$ \\
Female 1 & 98 & 77 & $78,6 \%$ \\
\hline
\end{tabular}

Table 2. Frequency of men's and women's codeswitching (Conversation 2).

\begin{tabular}{llll}
\hline Participants & Total utterances & Total switches & Frequency \\
\hline Male 5 & 47 & 23 & $48,9 \%$ \\
Male 6 & 33 & 23 & $69,7 \%$ \\
Female 2 & 46 & 39 & $84,8 \%$ \\
Female 3 & 40 & 15 & $37,5 \%$ \\
Female 4 & 65 & 54 & $83,1 \%$ \\
Female 5 & 25 & 23 & $92 \%$ \\
Female 6 & 16 & 11 & $68,75 \%$ \\
\hline
\end{tabular}

As mentioned, in conversation 1 there were five participants, among which one woman. The analysis shows that all these five bilinguals frequently codeswitch between Wolof and French while speaking. For example, table 1 
indicates that participant 1 produces $71,5 \%$ codeswitched instances out of his total utterances. This table also shows that participants 2 and 3 respectively used $71 \%$ and $76,9 \%$ of switched forms while the remaining two others made $80,5 \%$ and $78,6 \%$ of codeswitching in their speech.

In conversation 2, there were two male and five female participants. It has been noted that in the speech of two informants of these seven bilinguals, codeswitching is not as frequent as that of their peers. Table 2 indicates that the frequency of codeswitching in the speech of participants 6,2 , 4,5 and 6 is respectively $69,7 \% ; 84,8 \% ; 83,1 \% ; 92 \%$ and $68,75 \%$. On the hand, from this table one can see that participant 5 and 3 use less codeswitched forms which respectively represent $48,9 \%$ and $37,5 \%$ of their total utterances.

With respect to the first question of the study, investigating who codeswitch more frequently between men and women in this Wolof-French bilingual context, the analysis reveals that women use more codeswitched forms than men. After comparing the codeswitching instances in the speech of the 6 female participants to that of the 6 males, it has been indicated that women use a total of $74,04 \%$ codeswitched forms while men only use $69,75 \%$. These findings are in line with some previous studies such as Jagero and Odongo (Ebd) reporting that in Nairobi Kenya, women code switched more than men did.

Thus, these findings don't validate the first hypothesis set above. It was predicted that since codeswitching is a nonformal form of a language and men produce more non-formal forms in their speech, it was expected that men would codeswitch more frequently than their female counterparts. However, results of the present study show that women produce more codeswitched utterances than men in WolofFrench CS. The question of whether codeswitching is a formal form (prestigious) or a non-formal one can be raised here.

\subsection{Gender Variation in Codeswitching Types}

The second question of this research examines the type of codeswitching that men and women use more. Considering the total utterances of all the participants (including intrasentential, inter-sentential and unswitched forms), this variation is examined first at the individual level. This has been observed through each participant's intra-sentential and inter-sentential types of codeswitching. The findings are presented in tables 3 and 4 below.

Table 3. Type of codeswitching mostly used in male and female speech (Conversation 1).

\begin{tabular}{|c|c|c|c|c|c|c|c|}
\hline Participants & Total utterances & Unswitched forms & $\%$ & Intra-sentential & $\%$ & Inter-sentential & $\%$ \\
\hline Male 1 & 207 & 59 & $28,5 \%$ & 123 & $59,4 \%$ & 25 & $12,1 \%$ \\
\hline Male 2 & 69 & 20 & $29 \%$ & 34 & $49,3 \%$ & 15 & $21,7 \%$ \\
\hline Male 3 & 39 & 9 & $23,1 \%$ & 30 & $76,9 \%$ & 0 & \\
\hline Male 4 & 108 & 21 & $19,4 \%$ & 59 & $54,6 \%$ & 28 & $26 \%$ \\
\hline Female 1 & 98 & 21 & $21,4 \%$ & 67 & $68,4 \%$ & 10 & $10,2 \%$ \\
\hline
\end{tabular}

Table 4. Types of codeswitching mostly used in male and female speech (Conversation 2).

\begin{tabular}{|c|c|c|c|c|c|c|c|}
\hline Participants & Total utterances & Unswitched forms & $\%$ & Inra-sentential CS & $\%$ & Inter-sentential CS & $\%$ \\
\hline Male 5 & 47 & 24 & $51,1 \%$ & 17 & $36,2 \%$ & 6 & $12,8 \%$ \\
\hline Male 6 & 33 & 10 & $30,3 \%$ & 21 & $63,6 \%$ & 2 & $6,1 \%$ \\
\hline Female 2 & 46 & 7 & $15,2 \%$ & 28 & $60,9 \%$ & 11 & $24 \%$ \\
\hline Female 3 & 40 & 25 & $62,5 \%$ & 13 & $32,5 \%$ & 2 & $5 \%$ \\
\hline Female 4 & 65 & 11 & $16,9 \%$ & 43 & $66,1 \%$ & 11 & $16,9 \%$ \\
\hline Female 5 & 25 & 2 & $8 \%$ & 18 & $72 \%$ & 5 & $20 \%$ \\
\hline Female 6 & 16 & 5 & $31,25 \%$ & 11 & $68,75 \%$ & 0 & \\
\hline
\end{tabular}

The analysis shows that in both men's and women's codeswitching, the intra-sentential type is more frequent. For instance, tables 3 and 4 respectively presenting the total speech of both conversation 1 and conversation 2, indicate that the number of intra-sentential codeswitches of all the 12 participants is higher than their inter-sentential ones. In no instance, is a participant's amount of inter-sentential CS greater than their intra-sentential types.

With respect to the second research question, the results of this analysis indicate that women produce more intrasentential forms of codeswitching than men do. For instance, the total utterances of all the 6 men in tables 1 and 2 correspond to $56,66 \%$ of their speech. On the other hand, the intra-sentential codeswitched forms of the 6 female informants corresponds to $61,44 \%$ of their whole speech. It means that women use more intra-sentential codeswitched types than men $(61,44 \%$ against $56,66 \%)$. In contrast, this comparison of men's and women's codeswitching also indicates that, men produce the higher number of intersentential forms. For example, the total percentage of intersentential CS used in the 6 men's speech is $13,02 \%$ while that of these female counterparts' is $12,53 \%$.

The comparison of these 12 bilinguals' codeswitching types reveals that women produce more intra-sentential CS types than men and men produce a greater number of intersentential forms than women. These findings validate then the second hypothesis of this study.

\subsection{Gender Variation with the French Discourse Marker "Quoi"}

Beside frequency and types of codeswitching, the data has indicated that some French linguistic items can be present in the speech of one gender and be rare or even missing in the other. After analysing conversation 1 and 2, it is noted that 
the French discourse marker "quoi" is frequently used in men's speeches while it is totally missing in the speech of the female participants. We have listed 5 occurrences of this morpheme in conversation 1 ; and 3 others in conversation 2 that are all produced by men while any instance has been noted in women speeches. As a Wolof native speaker who daily codeswitches between Wolof and French, my observation also corroborates this finding. I have also noted that this French morpheme "quoi" can be used in female codeswitching but it is far more used by men than women. Examples of these types are given in example (1) and (2) below:

Conversation 1:

1. Jigéen bu sëye divorcer... dañu lay ragale xel quoi

(When a woman gets divorced guys tend to hesitate before wooing her)

Conversation 2:

2. Je pense que jikko yi ñoo yàqu quoi

(I admit that behaviours have changed)

\section{Conclusion}

Basing upon the findings, it is clear that the use of codeswitching is very frequent among Wolof educated people. Indeed, among the 12 participants of the study, only two use less than $50 \%$ of codeswitched forms in their speech $(37,5 \%$ and $48,9 \%)$. All the remaining 10 participants produce more than $68 \%$ of codeswitched instances out of their total utterances. This provides evidence that codeswitching is a hallmark of people in Wolof context as it is in all societies.

The analysis of the above data also reveals that gender plays a role in language variation. The comparison of men's and women's codeswitching shows that even if both genders practise codeswitching very frequently, women have been recognized to use it much more. Women use 74,04\% codeswitched forms in their total utterances against $69,75 \%$ for men.

The study also shows that not all types of codeswitching are frequent in Wolof bilinguals' speeches. The intrasentential form is far more used in both male and female codeswitching than the inter-sentential type.

The comparison of female and male speeches also indicates that women produce more intra-sentential forms of codeswitching than men. They use $61,44 \%$ of intra-sentential codeswitches while men only use $56,66 \%$ of this type. Men, on the other hand, produce more inter-sentential codeswitching instances than women $13,02 \%$ against $12,53 \%$ for the latter.

The above findings have finally shown that the insertion of the French discourse marker "quoi" varies in men's and women's Wolof language. This French morpheme is far more used by men than women.

Age has been identified in several studies as a factor in codeswitching and code choice. In this study, the participants can be divided into two groups. Some of them are below 30 years while the others above 30 years. The below 30 years are known to be in 20 s, meaning that they fall within the youth bracket while the above 30 are 'Senior Aged'. This seniority in age can be a reason for using longer constituents in both Wolof and French languages. It means that these speakers of more than 30 can produce more inter-sentential types of codeswitching than the senior bilinguals. While believing [10], this can be explained through the Negotiation Principle of Myers-Scotton's Markedness Model, stating that speakers of the same rank and age group share the same rights, obligations, attitudes and even aspirations. In this study, the 12 participants have different rank. Some have already got their Master degree and are office workers while the remaining others are undergraduate students. These speakers have also different age. That's why a future research could be conducted with a focus on rank and age in codeswitching, or in language in general. This would uncover more results in male and female speech.

\section{References}

[1] Amuzu, E. K. (2013). Socio-pragmatics of conversational code switching in Ghana. Ghana Journal of linguistics 1 (2), $1-22$.

[2] Backus, A. (1992a). Patters of language mixing: A study in Turkish-Dutch bilingualism. Wiesbaden: Otto Harrassowitz.

[3] Bokamba, E. (1989). Are there syntactic Constraints on Codemixing? World Englishes, 8 (3).

[4] Chan, B. (2009). Code-Switching between typologically distinct languages. In D. Bullock and A. J. Toribio (eds) The Cambridge Handbook of Linguistic Code (pp. 182-198). CUP.

[5] Deklu, G. (2014). Gender Variation in Ewe-English Codeswitching, University of Ghana.

[6] Dzameshie, A. F. (2001). Toward a Global Explanation of Unmarked Codeswitching: Evidence from Ewe-English Bilingual Codeswitching. Reading Working Papers in Linguistics 5, 1-21.

[7] Farida, P., Pandhiani, S. M, and Buriro, A. A. (2018). Codeswitching and Gender Identity. The Women Research Journal, Volume 10, 42-59.

[8] Faye, P, (2009), Etude du discours mixte et du code switching Français-Seereer-Wolof: Approches sociolinguistique et psycholinguistique, Thèse de doctorat, Dakar, UCAD.

[9] Gadner-Cloros, P (2009). Codeswitching. CUP.

[10] Jagero, N. and Odongo, E, K. (2001). Patterns and Motivations of Code Switching among Male and Female in Different Ranks and Age in Nairobi Kenya. International Journal of Linguistics 3 (1), 1-13.

[11] Kane, H. (2012), "Morphological and syntactic analysis of code switching: A contrastive study of Wolof-French and Wolof-English cases". Memoire of master, U. C. A. D, Dakar.

[12] Kane, H. (2019), "Grammatical aspects of codeswitching: a case study of Wolof-French in Senegal and Wolof-English in The Gambia". Unpublished thesis, U. C. A. D, Dakar. 
[13] Labov, William. (1966). The Social Stratification of English in New York City, Washington. DC: Center for applied linguistics.

[14] Legendre, G. and Schindler, M. (2010). Code switching in Urban Wolof: A case of violable constraint in syntax. ReVEL, special edition No. 4.

[15] Madeeha, N. and Shumaila, K. (2015). Motivation of codeswitching among female and male. European Journal of Academic Essays 2 (8): 1-5.

[16] Myers-Scotton, C. (1993a). Duelling languages: Grammatical structure in codeswitching. Oxford \& New York: Clarendon Press.

[17] Ndao, Papa Alioune (1996) "Contacts De Langues Au Sénégal. Etude Du Code Switching Wolof-français en Milieu Urbain: Approches Linguistique, Sociolinguistique et Pragmatique". Thèse de Doctorat d'Etat, Dakar, U. C. A. D.

[18] Poplack, S. (1980). "Sometimes I'll start a sentence in Spanish and termino en español": Toward a typology of code switching. Linguistics, 18, 581-618.
[19] Poplack, S. and Meechan, M. (1995). Patterns of language: Nominal structure in Wolof-French and Fongbe-French bilingual discourse. In Milroy L. and Muyesken, P. (eds), One speaker, Two languages. CUP.

[20] Subon, F. (2013). Gender Differences in the Use of Linguistic Forms in the Speech of Men and Women in the Malaysian Context. Journal of Humanities and Social Sciences, Volume 13, 67-79.

[21] Sunderland, Jane. (2009). Language and Gender: an advanced resource book. Milton: Routledge Applied Linguistics.

[22] Tannen, Deborah. (1990). You Just Don't Understand: Women and Men in Conversation. New York: Ballatine Books.

[23] Thiam, Nd. 1994. "La Variation Sociolinguistique Du Code Mixte Wolof-français à Dakar: Une Première Approche." Langage Et Société (Maison Des Sciences De l'Homme) 68: $11-34$.

[24] Trudgill, P. (1972). Sex, covert prestige and linguistic change in the urban British English of Norwich. Language in Society. Vol 1. No 2 pp: 179-195. 